\title{
Laparoscopic Transabdominal Repair for Lumbar Hernia: A Familiar Procedure for a Rare Problem
}

\author{
Hend Al-Nassar*, Mohomad Chour \\ Surgery Department, AlMoosa Specialist Hospital, Al-Ahsa, KSA \\ Email: *dr.chour@hotmail.com, hindalnassar_7@yahoo.com
}

How to cite this paper: Al-Nassar, H. and Chour, M. (2020) Laparoscopic Transabdominal Repair for Lumbar Hernia: A Familiar Procedure for a Rare Problem. Surgical Science, 11, 393-398. https://doi.org/10.4236/ss.2020.1112041

Received: October 2, 2020

Accepted: December 4, 2020

Published: December 7, 2020

Copyright $\odot 2020$ by author(s) and Scientific Research Publishing Inc. This work is licensed under the Creative Commons Attribution International License (CC BY 4.0).

http://creativecommons.org/licenses/by/4.0/

\begin{abstract}
Lumbar hernia is a protrusion of intraperitoneal or extraperitoneal tissues through posterior abdominal wall defect and is considered to be a rare condition. We present a case of 65 -year-old lady with primary spontaneous superior lumbar hernia treated laparoscopically, with the detailed operative steps and post-operative follow-up. With the growing experience in laparoscopic inguinal hernia repair, same technique, instruments and device used in transabdominal preperitoneal (TAPP) repair can be applied to treat selected cases of lumbar hernia with good outcome.
\end{abstract}

\section{Keywords}

Lumbar Hernia, Grynfeltt Hernia, Lumbar Triangle

\section{Introduction}

Lumbar hernias are considered to be a rare condition and very few cases are encountered in a surgeon's career. Approximately 300 cases have been published since the first reported case by Garangoet in 1731 [1].

Lumbar hernias are located in the Thoracolumbar region. It is a protrusion of intraperitoneal or extraperitoneal tissues through posterior abdominal wall defect. Further classification and description of boundaries was done by Petit (1783) and Grynfelt (1866) into inferior and superior triangles, respectively; apart from the site of their occurrence, there are different classifications of the lumbar hernias. They can be congenital or acquired. Acquired hernias can be spontaneous or secondary, with the latter being the most common etiology [2] [3] [4] [5].

A number of case reports about lumbar hernias could be found in the litera- 
ture, none of them discussing TAPP procedure in detail.

This report presents a case of primary spontaneous superior lumbar hernia treated laparoscopically, the first case to be published from Saudi Arabia.

The operative steps will be detailed to highlight the feasibility and the relative simplicity of this procedure.

\section{Case Report}

A 65 years old female, known case of type II Diabetes Mellitus on oral hypoglycemic medications, hypertension on valsartan and bronchial asthma on salbutamol nebulization when needed, presented with 6 months history of right loin pain.

The pain was dull in nature, increasing progressively with time, continuous, radiating to the pelvis with no aggravating or relieving factors. Patient denied any history of trauma or previous surgeries. She complained of dysuria and decrease in urine output, no Constipation or Change in Bowel habit, she was vitally stable, afebrile upon her presentation.

On examination, a right lumbar region mass measuring $6{ }^{*} 7 \mathrm{~cm}$ was palpated, it was tender on palpation with no overlying erythema or skin changes, not reducible, her abdomen otherwise was soft, non-tender, with positive bowel sounds.

Computerized tomography for the abdomen and pelvis was done with intravenous contrast and revealed a defect in the right lumbar posterior fascia, below the $12^{\text {th }}$ rib and lateral to the quadratus lumborum muscle. The hernia neck is located in the superior lumbar triangle in keeping with Grynfeltt hernia. The sac (measuring $8 \times 5 \mathrm{~cm}$ ) contains segment of the right upper ureter which is causing proximal hydroureter (Figure 1). After preoperative workup and preparation, the patient was planned for laparoscopic repair of the hernia. A cystoscopy

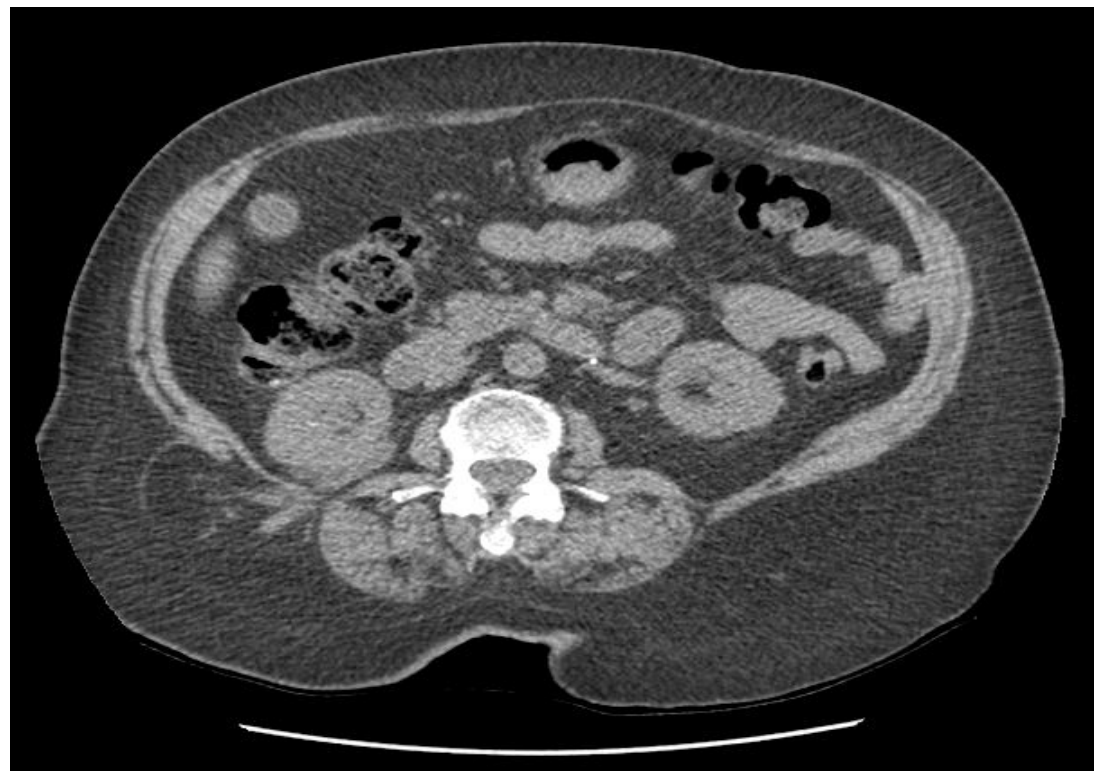

Figure 1. CT scan of abdomen and pelvis showing the hernia defect and the sac with fat content. 
was done and a Right ureteric stent was inserted under fluoroscopic guidance to facilitate intraoperative identification and sparing of the ureter. The patient was placed on left lateral decubitus position, abdomen access was gained through open technique at the level of the umbilicus on the midclavicular line with a 12 $\mathrm{mm}$ port, 2 other $5 \mathrm{~mm}$ ports were inserted under direct vision on the same right midclavicular line at the subcostal and the iliac crest level.

The peritoneum was incised just below the twelfth rib and incision continued downward around $15 \mathrm{~cm}$ in length (Figure 2), a preperitoneal dissection was carried out laterally, the defect was identified and content reduced (Figure 3 ).

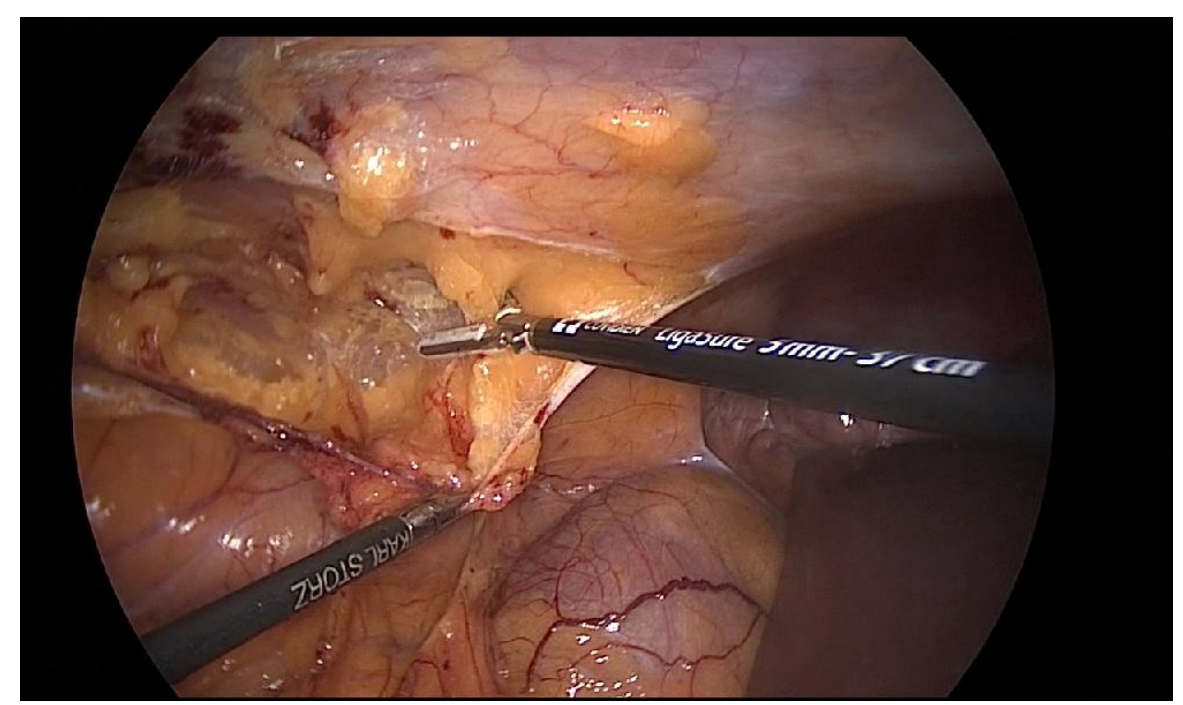

Figure 2. Creation of the preperitoneal dissection space using a combination of sharp and blunt dissection.

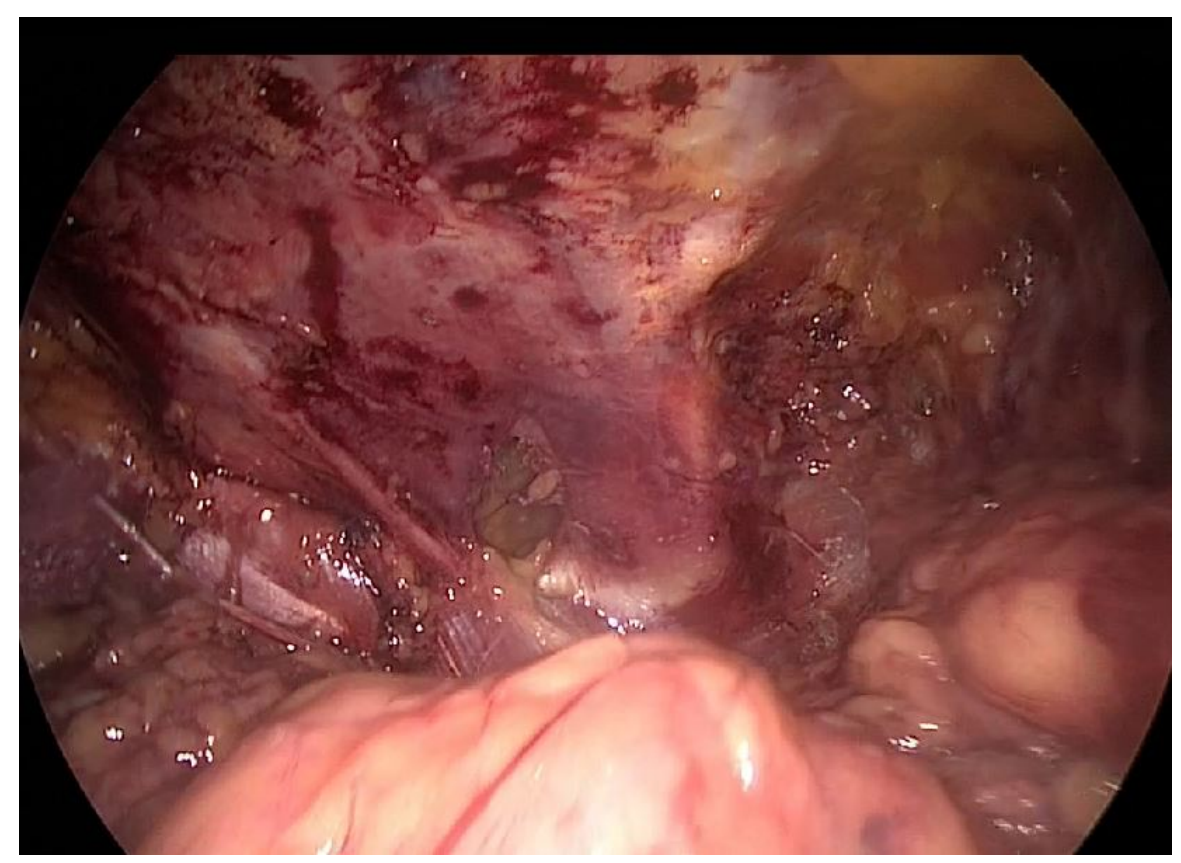

Figure 3. The hernia defect after content reduction. 


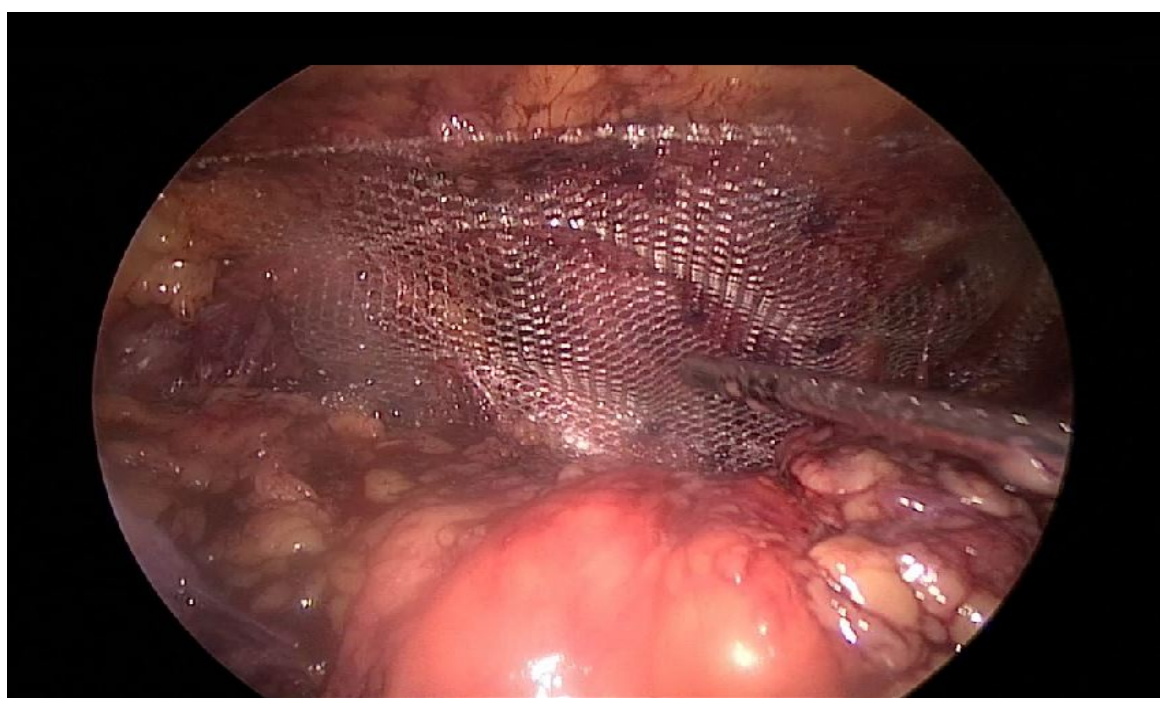

Figure 4. $15 \times 15$ Macroporous polyester mesh fixed in place using tacker device.

The defect was closed using 2.0 V-Loc ${ }^{\mathrm{TM}}$ suture and then reinforced with a 15 $\times 15 \mathrm{~cm}$ Parietex ${ }^{\mathrm{Tw}}$ lightweight monofilament mesh fixed in place using AbsorbaTack $^{\mathrm{TM}}$ fixation device (Figure 4), the peritoneum was then closed with 2.0 V-Loc ${ }^{\mathrm{TM}}$ sutures.

Patient tolerated well the procedure and discharged home on post-operative day 2, she was followed in clinic on day 7 then 14 and the ureteric stent was removed on day 21 under local anesthesia. She was pain free and the lumbar mass was clinically absent on follow up at 1 month and 6 months.

\section{Discussion}

Lumbar hernias may be congenital or acquired. Congenital hernias appear during infancy as the origin of a defect in the musculoskeletal system of the lumbar region and are associated with other malformations. Acquired lumbar hernias are usually primary-or spontaneous-and secondary, depending on the existence of a causal factor such as surgery, infection, or trauma. Predisposing factors in spontaneous acquired lumbar hernia are age, obesity, extreme thinness, chronic debilitating disease, muscular atrophy, intense slimming, chronic bronchitis, wound infection, and postoperative sepsis [6].

The most common clinical manifestation is a palpable mass that increases with coughing and strenuous activity, usually reducible and non-tender. Occasionally it can grow to a large size and alter the symmetry of the patient's torso. The patient usually reports unspecific abdominal discomfort, fatigue, or back pain. If the contents are renal, patients can experience urinary symptoms such as hematuria, oliguria, and colicky pain [7] [8].

There is a large range of differential diagnoses for a loin lump, which include hematomas, fibromas, sarcomas, abscesses and renal masses. The most published misdiagnosis, however, is lipoma. There are documented cases of lipoma extraction by surgery followed by a consistent mass being explained as a lumbar 
hernia [1]. When history and physical exam raise concern for lumbar hernia, CT scan is the preferred modality for confirming the diagnoses as well as delineating the muscular and fascial layers and the contents within the hernia sac [9]. Most of the patients are treated as elective cases, and only $9 \%$ present as a surgical emergency. The treatment of choice has always been surgical repair, and once the diagnosis has been made, these patients should be treated to avoid complications.

Many techniques have been described for surgical repair of lumbar hernias, with an incision from the $12^{\text {th }}$ rib to the iliac crest, including primary repair, local tissue flaps, only fascial flaps, and conventional prosthetic mesh repair [10].

Burick and Parascandola performed the first repair by transabdominal laparoscopic approach in 1996 [11]. Woodward and colleagues introduced the balloon dissector for a total extra-peritoneal approach in 1999 [12].

In our institution we have a wide experience in treating inguinal and ventral hernias both open and laparoscopically. This was the first diagnosed lumbar hernia case in our hospital and the first in most of our surgeons' career. After reviewing the CT scan and using a multidisciplinary discussion with our urology and radiology colleagues, we decided to treat it laparoscopically using the same techniques and basics of a TAPP. After ureteral stent placement and lateral position, the procedure length was 90 minutes, similar to a TAPP procedure no special instruments or device were used, the patient tolerated the procedure and discharged in reasonable time

In our case even though the hernia was big $(8 \mathrm{~cm})$, but the small size $(2 \mathrm{~cm})$ of the defect made its repair easy. The challenge in this technique will be faced with large defects more than $5 \mathrm{~cm}$, with traumatic or incisional hernias and with hernias containing bowel or other structures.

With the evolution of laparoscopy and the growing use of robotics in hernia surgeries, more procedures on more complex cases should be reported, comparative studies with other techniques should be done, evaluating recurrence rate and patient satisfaction.

\section{Conclusions}

Lumbar hernias are uncommon to encounter, as they are rare type of hernia. It can be a challenge to diagnose it initially. Few cases can present as emergency case; however the majority of lumbar hernias are treated electively.

With good preoperative assessment and selection, and based on a solid experience in laparoscopic inguinal and ventral hernia repair, same techniques can be used to treat lumbar hernias. The transabdominal preperitoneal TAPP approach is relatively easy to perform with excellent patient tolerability and good short and medium-term outcome.

\section{Conflicts of Interest}

The authors declare no conflicts of interest regarding the publication of this paper. 


\section{References}

[1] Kadler, B., Shetye, A., Patten, D.K. and Al-Nowfal, A. (2019) A Primary Inferior Lumbar Hernia Misdiagnosed as a Lipoma. Annals of the Royal College of Surgeons of England, 101, e96-e98. https://doi.org/10.1308/rcsann.2019.0009

[2] Pachani, A.B., Reza, A., Jadhav, R.V. and Mathews, S. (2011) A Primary Idiopathic Superior Lumbar Triangle Hernia with Congenital Right Scoliosis: A Rare Clinical Presentation and Management. International Journal of Applied and Basic Medical Research, 1, 60-62. https://doi.org/10.4103/2229-516X.81985

[3] Hussain, A., Slesser, A.A., Monib, S., Maalo, J., Soskin, M. and Arbuckle, J. (2014) A De Garengeot Hernia Masquerading as a Strangulated Femoral Hernia. International Journal of Surgery Case Reports, 5, 656-658. https://doi.org/10.1016/j.ijscr.2014.08.001

[4] Stamatiou, D., Skandalakis, J.E., Skandalakis, L.J. and Mirilas, P. (2009) Lumbar Hernia: Surgical Anatomy, Embryology, and Technique of Repair. The American Surgeon, 75, 202-207. https://doi.org/10.1177/000313480907500303

[5] Walgamage, T.B., Ramesh, B.S. and Alsawafi, Y. (2015) Case Report and Review of Lumbar Hernia. International Journal of Surgery Case Reports, 6C, 230-232. https://doi.org/10.1016/j.ijscr.2014.07.022

[6] Moreno-Egea, A., Baena, E.G., Calle, M.C., Martínez, J.A. and Albasini, J.L. (2007) Controversies in the Current Management of Lumbar Hernias. Archives of Surgery, 142, 82-88. https://doi.org/10.1001/archsurg.142.1.82

[7] Presti Jr., J.C. and Narayan, P. (1988) Lumbar Herniation of the Kidney. Journal of Urology, 140, 586-587. https://doi.org/10.1016/S0022-5347(17)41726-5

[8] Pang, R.R. and Makowski, A.L. (2019) Inferior Lumbar Triangle Hernia with Incarceration. American Journal of Emergency Medicine, 37, 1218.e5-1218.e6. https://doi.org/10.1016/j.ajem.2019.04.011

[9] Arca, M.J., Heniford, B.T., Pokorny, R., Wilson, M.A., Mayes, J. and Gagner, M. (199) Laparoscopic Repair of Lumbar Hernias. Journal of the American College of Surgeons, 187, 147-152. https://doi.org/10.1016/S1072-7515(98)00124-0

[10] Heniford, B.T., Iannitti D.A. and Gagner, M. (1997) Laparoscopic Inferior and Superior Lumbar Hernia Repair. Archives of Surgery, 132, 1141-1144. https://doi.org/10.1001/archsurg.1997.01430340095017

[11] Burick, A.J. and Parascandola, S.A. (1996) Laparoscopic Repair of a Traumatic Lumbar Hernia: A Case Report. Journal of Laparoendoscopic Surgery, 6, 259-262. https://doi.org/10.1089/lps.1996.6.259

[12] Woodward, A.M., Flint, L.M. and Ferrara, J.J. (1999) Laparoscopic Retroperitoneal Repair of Recurrent Postoperative Lumbar Hernia. Journal of Laparoendoscopic \& Advanced Surgical Techniques, 9, 181-186. https://doi.org/10.1089/lap.1999.9.181 